Article

\title{
Analysis of Sildenafil in Liquor and Health Wine Using Surface Enhanced Raman Spectroscopy
}

\author{
Shupei Xiao ${ }^{1,2}$ and Yong $\mathrm{He}^{1,2, *(1)}$ \\ 1 College of Biosystems Engineering and Food Science, Zhejiang University, Hangzhou 310058, China; \\ 180312@zju.edu.cn \\ 2 Key Laboratory of Spectroscopy Sensing, Ministry of Agriculture, Zhejiang University, \\ Hangzhou 310058, China \\ * Correspondence: yhe@zju.edu.cn; Tel.: +86-0571-8898-2143
}

Received: 14 May 2019; Accepted: 31 May 2019; Published: 3 June 2019

\begin{abstract}
The illegal adulteration of sildenafil in herbal food supplements and alcoholic drinks immensely threatens human health due to its harmful side-effects. Therefore, it is important to accurately detect and identify the presence of sildenafil in alcoholic drinks. In this study, Opto Trace Raman 202 (OTR 202) was used as surface enhanced Raman spectroscopy (SERS) active colloids to detect sildenafil. The results demonstrated that the Raman enhancement factor (EF) of OTR 202 colloids reached $1.84 \times 10^{7}$ and the limits of detection (LODs) of sildenafil in health wine and liquor were found to be as low as $0.1 \mathrm{mg} / \mathrm{L}$. Moreover, the SERS peaks of $645,814,1235,1401,1530$ and $1584 \mathrm{~cm}^{-1}$ could be qualitatively determined as sildenafil characteristic peaks and the relationship between Raman peak intensity and sildenafil concentration in health wine and liquor were different. There was a good linear correlation between Raman peak intensity, and sildenafil concentration in health wine ranged $0.1-1 \mathrm{mg} / \mathrm{L}\left(0.9687<R^{2}<0.9891\right)$ and $1-10 \mathrm{mg} / \mathrm{L}\left(0.9701<R^{2}<0.9840\right)$, and in liquor ranged $0.1-1 \mathrm{mg} / \mathrm{L}\left(0.9662<R^{2}<0.9944\right)$ and $1-20 \mathrm{mg} / \mathrm{L}\left(0.9625<R^{2}<0.9922\right)$. The relative standard deviations (RSD) were less than $5.90 \%$ (sildenafil in health wine) and $9.16 \%$ (sildenafil in liquor). The recovery ranged $88.92-104.42 \%$ (sildenafil in health wine) and $90.09-104.55 \%$ (sildenafil in liquor). In general, the sildenafil in health wine and liquor could be rapidly and quantitatively determined using SERS technique, which offered a simple and accurate alternative for the determination of sildenafil in alcoholic drinks.
\end{abstract}

Keywords: sildenafil; surface-enhanced Raman spectroscopy; health wine; liquor; limit of detection; quantitative determination; linear relationship

\section{Introduction}

Sildenafil is one of the inhibitors of phosphodiesterase type 5 (PDE-5), which is frequently added into health supplementary products for the treatment of erectile dysfunction (ED) in males [1]. Due to its side-effects such as headache, dyspepsia, back pain, rhinitis and flu syndrome, the usage of sildenafil must be strictly controlled by medical supervision [2,3]. Several investigations have indicated that sildenafil has been illegally adulterated into some dietary supplements, herbal medicines and alcoholic drinks [4-7]. Limited by the complicated sample processing and extraction, traditional methods for determining sildenafil mainly focus on high-performance liquid chromatography (HPLC) [8,9], ultraviolet spectrophotometry (UV) [10,11], gas chromatography-mass spectrometry (GC-MS) [12,13], thin layer chromatography (TLC) [14,15] and near infrared spectrometry (NIR) [16,17]. Ramirez et al. [18] quantified plasma levels of sildenafil and its metabolite by liquid chromatography (LC) with a $C_{18}$ reverse-phase column and UV detection; the limits of detection (LODs) and quantification were 1 and $10 \mathrm{ng} / \mathrm{mL}$, respectively. Oris et al. [19] determined ardenafil, sildenafil, tadalafil, testosterone, procaine, 
lidocaine, prilocaine, and benzocaine in cosmetic creams by using HPLC method with ultraviolet diode array (UV-DAD) and electrospray ionization mass spectrometry (ESI-MS). The results show a good determination coefficient $\left(R^{2} \geq 0.99\right)$ and the limits of quantification range $2.5-7.8 \mu \mathrm{g} / \mathrm{g}$ and $3.3-8.9 \mathrm{ng} / \mathrm{g}$ for HPLC-UV-DAD assay and HPLC-ESI-MS assay, respectively. Kee et al. [20] differentiated two groups of PDE-5 inhibitors including four sildenafil- and three thiosildenafil-like analogs by Orbitrap-mass spectrometry, indicating that the identification of PDE- 5 analogs in dietary supplements can be possibly done in a wide concentration range. Liew et al. [21] applied ultra-fast liquid chromatography (UFLC) with ESI-MS/MS to quantify sildenafil and $N$-desmethyl sildenafil. The linear concentration ranges of sildenafil and $N$-desmethyl sildenafil are 10-800 ng/mL and 10-600 ng/mL, respectively, and the correlation coefficients are $R^{2} \geq 0.9976$ and $R^{2} \geq 0.9992$ respectively. Yaroshenko et al. [22] determined the sildenafil in blood plasma using HPLC with UV and mass-spectrometry (MS). The results show that the limits of quantification of sildenafil are 20 and $5 \mathrm{ng} / \mathrm{mL}$ using HPLC-UV and HPLC-MS methods, respectively.

Although the traditional methods for determining sildenafil achieve high sensibility, the complex and time-consuming sample pretreatment process, huge instruments and high cost limit their developments. Compared with the methods mentioned above, surface enhanced Raman spectroscopy (SERS) shows great potential on ultrasensitive and label-free chemical or biochemical analysis based on its advantages of simple sample treatment and fast sample screening speed [23,24]. Recently, some researchers applied SERS technique for the determination of sildenafil and its analogs. Lv et al. [25] proposed a SERS method based on a solid-phase dendritic Ag nanostructure for the trace detection of sildenafil, and the superiority in practical application of SERS technique is verified through the Raman spectroscopy (RS) of sildenafil within 1150-1699 $\mathrm{cm}^{-1}$. Liu et al. [15] investigated the characteristics and influencing factors of sildenafil on the thin layers chromatographic surface-enhanced Raman spectroscopy (TLC-SERS). The results suggest that the peaks at 1563, 1530, 1405, 1240 and $1272 \mathrm{~cm}^{-1}$ can be determined as sildenafil characteristic peaks. They did not mention the LOD of sildenafil. Mao et al. [26] used the micro-Raman spectroscopy as a non-destructive technique to screen sildenafil and tadalafil adulterated in the healthcare products, and confirms the detection results with wavelet transform (WT) by LC/MS measurements. Zhao et al. [27] used SERS technique to detect the illegally-added sildenafil in drugs. The results show that the sildenafil in aqueous solutions as low as $1 \mathrm{mg} / \mathrm{L}$ can be semi-quantitatively detected with high signal uniformity (RSD $=3.77 \%)$. Zhang et al. [28] applied SERS analysis method for the simultaneous detection of five types of illegal chemical drugs added in Chinese proprietary medicines. Wu et al. [29] applied SERS with sodium alginate (SA)-silver nanoparticles (AgNPs) substrates for the determination of vardenafil and rosiglitazone maleate (ROS) in natural healthcare products. The LOD and ROS of vardenafil are as low as 1.63 and $2.20 \mathrm{mg} / \mathrm{L}$, respectively. Lin et al. [30] applied SERS to detect sildenafil in cocktail, and the LOD reaches $0.1 \mathrm{mg} / \mathrm{L}$. However, in practice, there are few cases of sildenafil in cocktails, while there are many studies based on sildenafil determination in liquor and health wine. Although the partial least squares (PLS) nonlinear model effect is good, for the quantitative detection of SERS, the single peak used in this study was more convincing.

Based on the analysis mentioned above, it is important to accurately detect sildenafil in alcoholic drinks such as health wine and liquor using SERS. In this study, the Opto Trace Raman 202 (OTR 202) was used as SERS active colloids. The characterization of OTR 202 colloids were studied and the Raman enhancement factor (EF) of OTR 202 colloids was calculated. Besides, the relationship between Raman peak intensity and sildenafil concentration in health wine and liquor were established to realize the quantitative determination of sildenafil. 


\section{Results and Discussion}

\subsection{Characterization of Opto Trace Raman 202}

Figure 1a,b presents representative TEM images of Opto Trace Raman 202 colloids at 200 nm scale and $50 \mathrm{~nm}$ scale, respectively. The UV spectroscopy of OTR 202 colloids is given in Figure 1c.
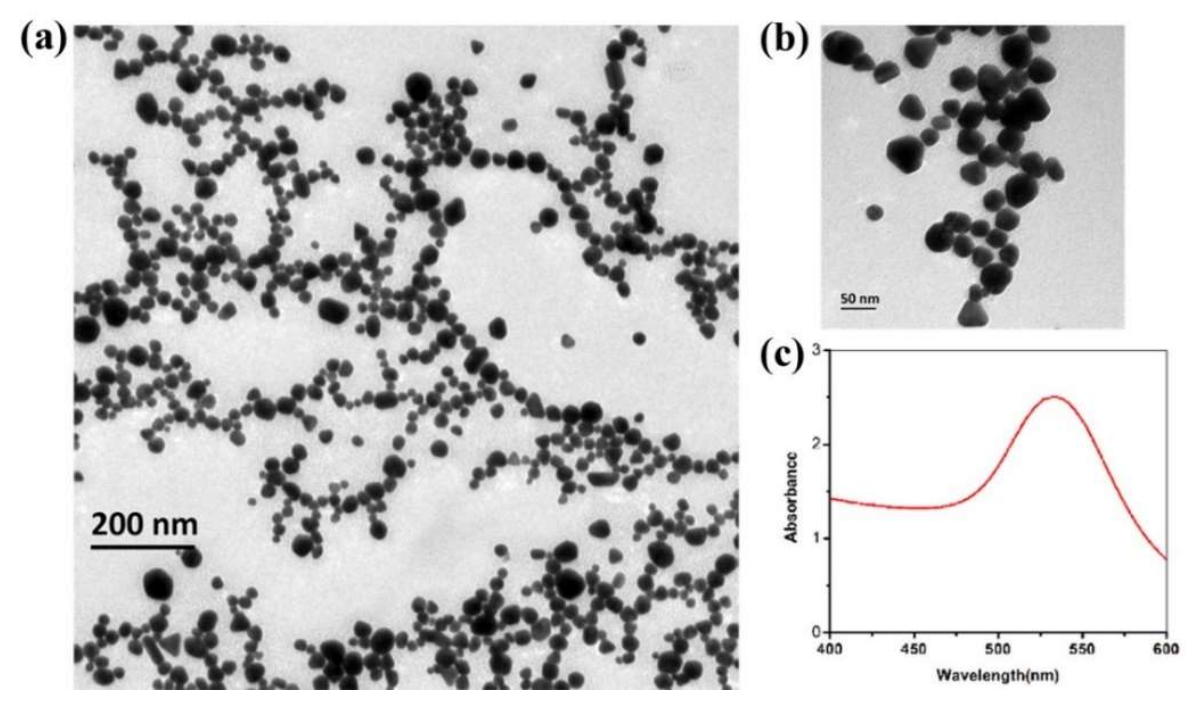

Figure 1. Transmission electron microscopy (TEM) images of Opto Trace Raman 202 (OTR 202) at: $200 \mathrm{~nm}$ scale (a); and $50 \mathrm{~nm}$ scale (b). The ultraviolet spectrophotometry (UV) spectroscopy of OTR 202 (c).

It can be clearly seen that the diameter of OTR 202 colloids was not very uniform and the shape of OTR 202 colloids was not a regular sphere. The diameter of OTR 202 colloids was in the range of 20-50 $\mathrm{nm}$ and the UV/Visible characteristic absorption peaks of OTR 202 colloids was at $533 \mathrm{~nm}$ within the band of gold nanoparticles (AuNPs) ranging from 450 to $600 \mathrm{~nm}$ [31] (Figure 1c). Compared with the results of Dong et al. [32,33] (AuNPs: $27.8 \mathrm{~nm}$; UV/Visible characteristic absorption peaks: $543 \mathrm{~nm}$ ), Luo et al. [34] (AuNPs: 23-102 nm; UV/Visible characteristic absorption peaks: 525-549 nm) and He et al. [24] (AuNPs: 41-50 nm; UV/Visible characteristic absorption peaks: 525-540 nm), we could infer that the properties of OTR 202 colloids were consistent with AuNPs colloids. Therefore, the OTR 202 colloids was suitable as SERS substrate in this paper. Compared with Lin's [30] study, the properties of OTR 202 data were more convincing.

\subsection{The SERS Performance of Rhodamine 6G Substrate}

In this study, Rhodamine 6G (R6G) was used as a probe to investigate SERS activity of OTR 202 colloids. Furthermore, the SERS spectra of R6G with different concentrations were obtained, as shown in Figure 2.

As shown in Figure 2, the RS of $10^{-2} \mathrm{M}$ R6G only had a faint signal. However, the LOD of R6G could reach $5 \times 10^{-8} \mathrm{M}$ when the R6G was mixed with OTR 202 colloids. The Raman EF was used to measure the enhancement effect, which was calculated as follows [35]:

$$
\mathrm{EF}=\frac{I_{\mathrm{SERS}} C_{\text {Raman }}}{I_{\text {Raman }} C_{\mathrm{SERS}}}
$$

where $I_{\text {SERS }}$ is the integrated intensity of R6G molecules adsorbed on the colloids surface; $I_{\text {Raman }}$ is the integrated intensity of the same Raman band obtained without the OTR 202 colloids; $C_{\text {SERS }}$ represents the concentration of R6G adsorbed on OTR 202 colloids; and $C_{\text {Raman }}$ represents the concentration of R6G that can be detected by ordinary RS. 


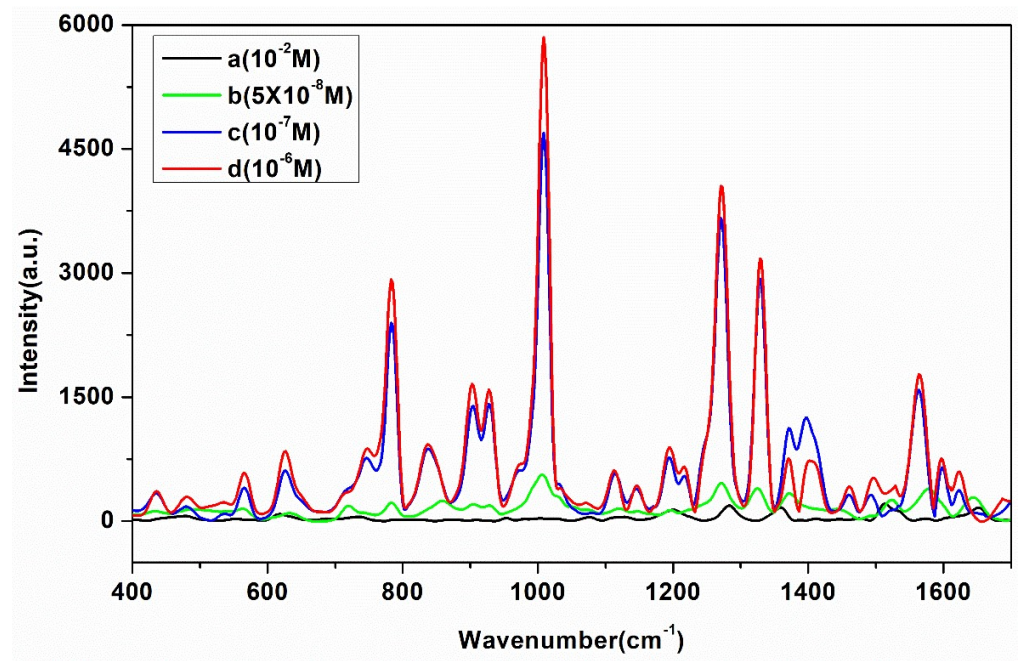

Figure 2. (a) Raman spectroscopy (RS) of $10^{-2} \mathrm{M}$ Rhodamine 6G (R6G); and surface enhanced Raman spectroscopy (SERS) spectra of R6G with different concentrations: (b) $5 \times 10^{-8} \mathrm{M}$; (c) $10^{-7} \mathrm{M}$; and (d) $10^{-6} \mathrm{M}$.

In this work, the values of $C_{\text {SERS }}$ and $C_{\text {Raman }}$ were $10^{-7} \mathrm{M}$ and $10^{-2} \mathrm{M}$, respectively. The conditions for Raman and SERS measurement were kept constant. The ratio of $I_{S E R S} / I_{\text {Raman }}$ from the Raman intensities at 784, 1010, 1272 and $1330 \mathrm{~cm}^{-1}$ were calculated, as shown in Table 1. It can be clearly seen that the OTR 202 colloids exhibited high EF of R6G, especially at $1331 \mathrm{~cm}^{-1}$ with an EF of $1.84 \times 10^{7}$, which indicated that the SERS had high sensitivity and stability based on OTR 202 colloids.

Table 1. The enhancement factor (EF) of R6G based on OTR 202 colloids.

\begin{tabular}{cccccc}
\hline Wavenumber $\left(\mathbf{c m}^{-\mathbf{1}}\right)$ & $\boldsymbol{I}_{\text {Raman }}$ & $\boldsymbol{I}_{\text {SERS }}$ & $\boldsymbol{I}_{\text {SERS }} / \boldsymbol{I}_{\text {Raman }}$ & $\boldsymbol{C}_{\text {SERS }} / \boldsymbol{C}_{\text {Raman }}$ & EF \\
\hline 785 & 17 & 2377 & 140 & & $1.40 \times 10^{7}$ \\
1009 & 32 & 4697 & 149 & & $10^{5}$ \\
1271 & 102 & 3665 & 36 & & $3.6 \times 10^{6}$ \\
1331 & 16 & 2928 & 184 & & $1.84 \times 10^{7}$ \\
\hline
\end{tabular}

\subsection{The SERS Performance of Sildenafil}

To investigate the sensitivity and stability of the OTR 202 colloids for the detection of sildenafil in health wine and liquor, the normal RS of sildenafil (molecular formula: $\mathrm{C}_{22} \mathrm{H}_{30} \mathrm{~N}_{6} \mathrm{O}_{4} \mathrm{~S}$ ) powder, the SERS of $100 \mathrm{mg} / \mathrm{L}$ solution mixed with methanol, the SERS of $100 \mathrm{mg} / \mathrm{L}$ sildenafil in liquor, and the SERS of $100 \mathrm{mg} / \mathrm{L}$ sildenafil in health wine were collected, as shown in Figure 3. The detailed vibrational modes of sildenafil are listed in Table 2 .

Table 2. The proposed assignment of sildenafil Raman peaks.

\begin{tabular}{|c|c|c|c|c|}
\hline $\begin{array}{l}\text { RS of Sildenafil } \\
\text { Powder }\left(\mathrm{cm}^{-1}\right)\end{array}$ & $\begin{array}{l}\text { SERS of Sildenafil } \\
\text { Solution }\left(\mathrm{cm}^{-1}\right)\end{array}$ & $\begin{array}{l}\text { SERS of Sildenafil } \\
\text { in Liquor }\left(\mathrm{cm}^{-1}\right)\end{array}$ & $\begin{array}{c}\text { SERS of Sildenafil in } \\
\text { Health Wine }\left(\mathrm{cm}^{-1}\right)\end{array}$ & Assignments \\
\hline 472 & 474 & 470 & 490 & $v$ carbonyl $+\delta$ phenetole \\
\hline 553 & 553 & 557 & 553 & $v$ carbonyl $+\delta$ phenetole \\
\hline 647 & 647 & 645 & 645 & $v$ carbonyl $+\delta$ phenetole $+v(\mathrm{C}-\mathrm{S})$ \\
\hline 744 & 723 & 723 & 730 & $v$ carbonyl $+\delta$ phenetole $+v(C-S)$ \\
\hline 812 & 812 & 814 & 814 & $v$ Pyrazole pyridine \\
\hline 926 & 926 & 923 & 923 & $\delta(\mathrm{C}-\mathrm{C})+v(\mathrm{C}-\mathrm{H})$ \\
\hline 992 & 989 & 991 & 991 & $v(\mathrm{C}-\mathrm{H})$ in carbonyl \\
\hline 1027 & 1045 & 1043 & 1043 & $\delta(\mathrm{C}-\mathrm{C})+v(\mathrm{C}-\mathrm{H})$ \\
\hline 1150 & 1159 & 1162 & 1151 & $v(\mathrm{C}-\mathrm{H})$ in carbonyl \\
\hline 1232 & 1232 & 1232 & 1232 & $v(\mathrm{C}-\mathrm{H})$ in carbonyl \\
\hline 1310 & 1301 & 1309 & 1309 & $\delta(\mathrm{C}-\mathrm{H})$ in ethyl \\
\hline 1396 & 1401 & 1401 & 1401 & $\delta(\mathrm{C}-\mathrm{H})$ in methyl piperazine \\
\hline 1487 & 1487 & 1487 & 1487 & $\delta(\mathrm{C}-\mathrm{H})$ in Pyrazole pyridine \\
\hline 1528 & 1528 & 1530 & 1530 & $v(\mathrm{C}-\mathrm{H})$ in Pyrazole pyridine \\
\hline 1583 & 1582 & 1582 & 1582 & $\delta(\mathrm{C}-\mathrm{H})$ in Pyrazole pyridine \\
\hline
\end{tabular}




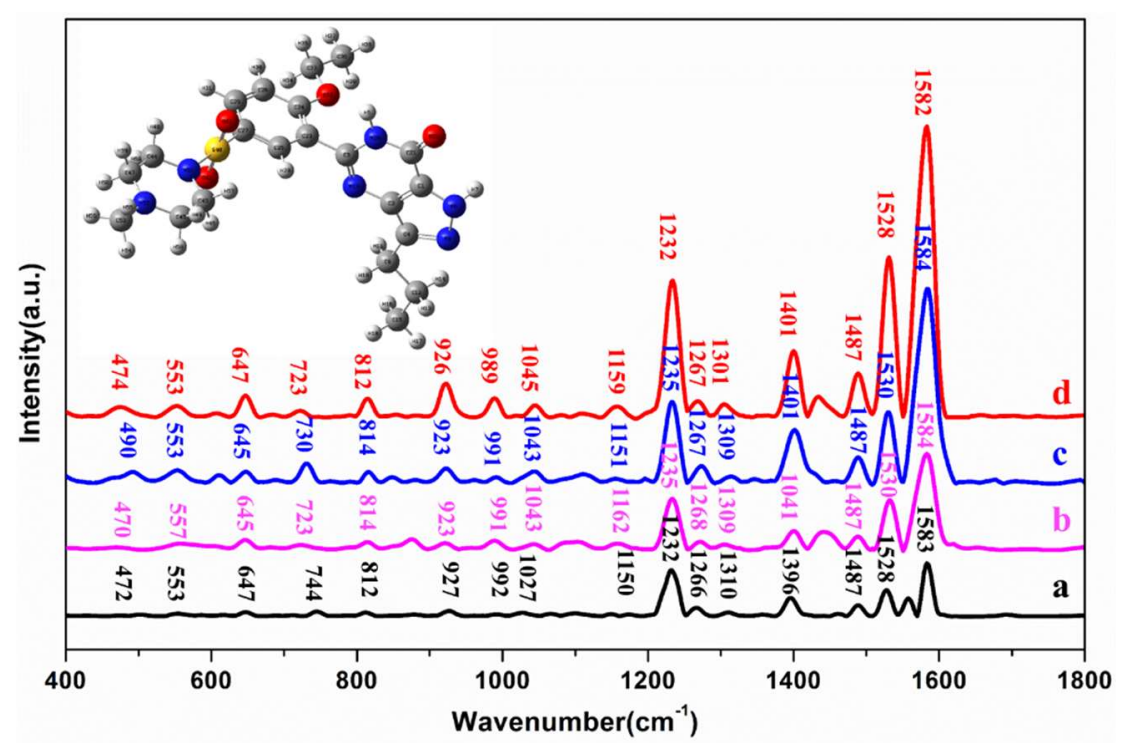

Figure 3. (a) RS of powder sildenafil; (b) SERS spectra of sildenafil in liquor; (c) SERS spectra of sildenafil in health wine; and (d) SERS spectra of sildenafil solution mixed with methanol. Inset: The molecular structure of sildenafil.

Clearly, the SERS signals of sildenafil solution were stronger than those of sildenafil in liquor and health wine. The normal Raman peaks of sildenafil were in good agreement with the previous literature [27], and the SERS of sildenafil in liquor and health wine were basically similar to the SERS of sildenafil solution, whose Raman shifts (less than $10 \mathrm{~cm}^{-1}$ ) were within a reasonable range, which indicated that the position of SERS peaks detected by SERS spectra based on OTR 202 colloids were feasible and reliable.

According to density functional theory (DFT) calculation based on the B3LYP/6-31G (d,p) method in Gaussian v.09 software [36], the peaks at 472 and $553 \mathrm{~cm}^{-1}$ could be assigned to carbonyl stretching and phenetole breathing deformable vibration; the peaks at 647 and $723 \mathrm{~cm}^{-1}$ were derived from the carbonyl stretching, phenetole deformable vibration and C-S stretching in sulfamide; $812 \mathrm{~cm}^{-1}$ belonged to the pyrazole pyridine stretching; the peaks located at 926 and $1027 \mathrm{~cm}^{-1}$ were all related to $\mathrm{C}-\mathrm{C}$ deformable vibration and $\mathrm{C}-\mathrm{H}$ stretching in pyrazole pyridine group; the peaks at 989,1159 and $1232 \mathrm{~cm}^{-1}$ were the $\mathrm{C}-\mathrm{H}$ stretching vibration in carbonyl; $1310 \mathrm{~cm}^{-1}$ was $\mathrm{C}-\mathrm{H}$ stretching vibration in ethyl; $1401 \mathrm{~cm}^{-1}$ was the $\mathrm{C}-\mathrm{H}$ deformable vibration in methyl piperazine; and 1487, 1528 and $1582 \mathrm{~cm}^{-1}$ were the $\mathrm{C}-\mathrm{H}$ deformable vibration in pyrazole pyridine.

\subsection{Detection of Sildenafil in Health Wine and Liquor}

Furthermore, we investigated the accuracy and stability of OTR 202 colloids for the detection of sildenafil in health wine and liquor. The representative SERS spectra of sildenafil in health wine and liquor with different concentrations are given in Figure 4. The SERS of sildenafil concentration ranged from 0 to $50 \mathrm{mg} / \mathrm{L}(0,0.1,0.2,0.4,0.6,0.8,1,2,4,6,8,10,15,20,25,30,35,40,45$ and $50 \mathrm{mg} / \mathrm{L})$ in health wine and liquor were obtained and the SERS peaks at 645, 814, 1232, 1401, 1530 and $1582 \mathrm{~cm}^{-1}$ are shown in Figure 5. 

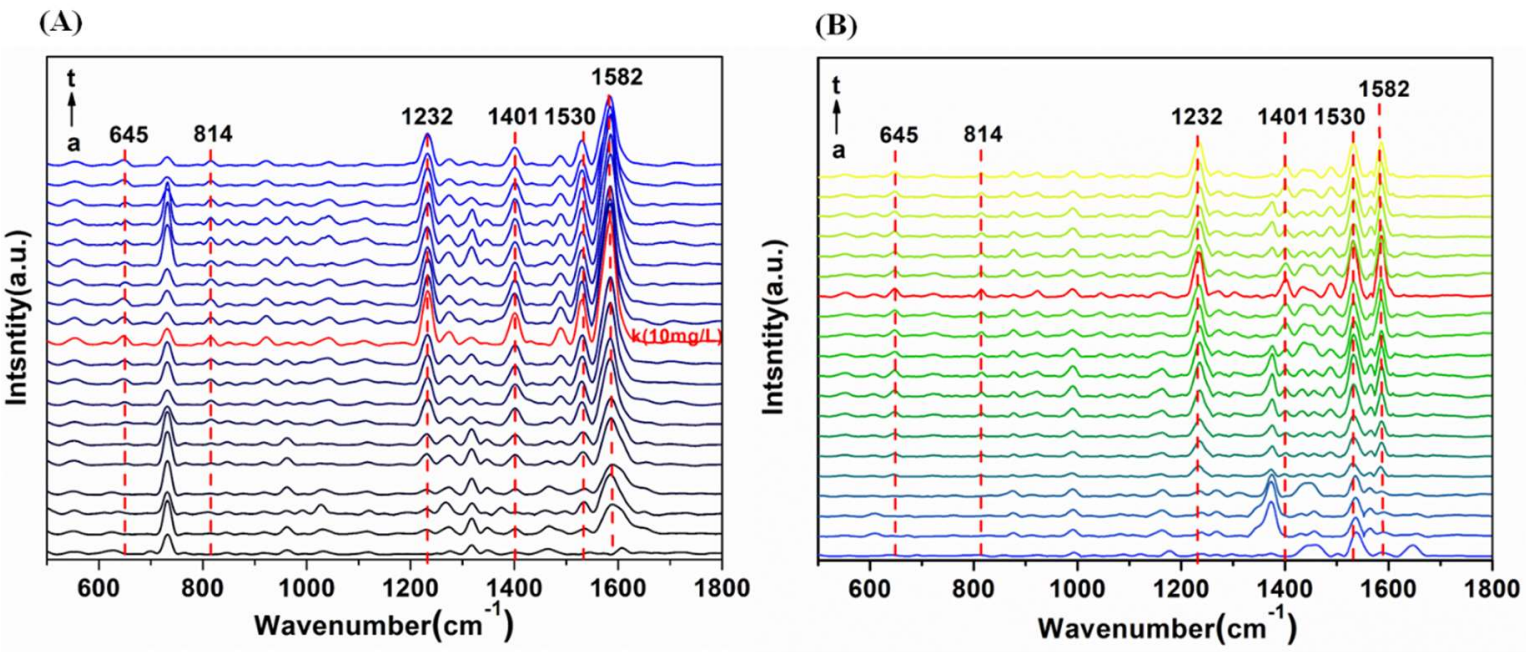

Figure 4. SERS spectra of sildenafil in health wine (A) and liquor (B) with different concentrations (from a to t: $0,0.1,0.2,0.4,0.6,0.8,1,2,4,6,8,10,15,20,25,30,35,40,45$ and $50 \mathrm{mg} / \mathrm{L}$, respectively).

(A)

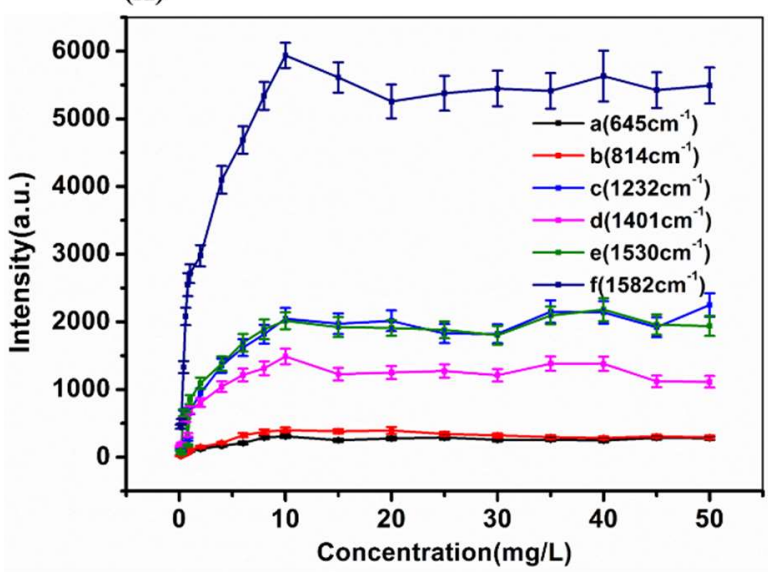

(B)

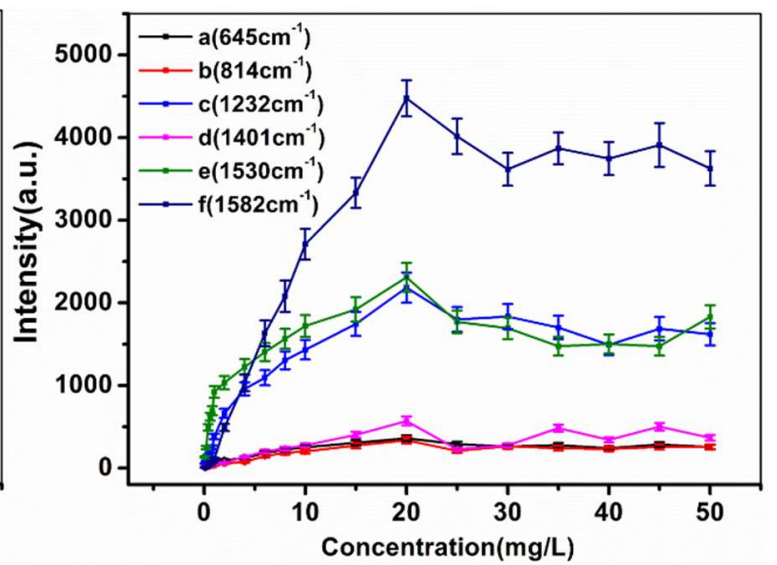

Figure 5. The SERS peak intensities of sildenafil concentration ranging from $0.1 \mathrm{mg} / \mathrm{L}$ to $50 \mathrm{mg} / \mathrm{L}$ in health wine (A) and liquor (B) at: $645 \mathrm{~cm}^{-1}$ (a); $814 \mathrm{~cm}^{-1}$ (b); $1232 \mathrm{~cm}^{-1}$ (c); $1401 \mathrm{~cm}^{-1}$ (d); $1530 \mathrm{~cm}^{-1}$ (e); and $1582 \mathrm{~cm}^{-1}$ (f).

As shown in Figures 4 and 5, with the increase of sildenafil in health wine from $0.1 \mathrm{mg} / \mathrm{L}$ to $50 \mathrm{mg} / \mathrm{L}$, the SERS peaks at 645, 814,1232, 1401, 1530 and $1582 \mathrm{~cm}^{-1}$ increased sharply within the range of $0.1-10 \mathrm{mg} / \mathrm{L}$, while they slowly increased wh en the sildenafil concentration continued to increase from 10 to $50 \mathrm{mg} / \mathrm{L}$. In addition, when the sildenafil concentration in health wine increased from 10 to $50 \mathrm{mg} / \mathrm{L}$, the intensities of SERS peaks at $645,814,1232,1401,1530$ and $1582 \mathrm{~cm}^{-1}$ basically did not change. It was found that the sildenafil in health wine could still be identified even when the sildenafil solution concentration was as low as $0.1 \mathrm{mg} / \mathrm{L}$. Compared with the previous research [27,29] with LODs of $1,1.63$ and $2.20 \mathrm{mg} / \mathrm{L}$, the LOD of sildenafil in this study was improved greatly; both were far lower than $1 \%$. Thus, the presented method can be successfully applied for the quantification of real natural healthcare products. In addition, there were SERS peaks at 730, 940 and $1310 \mathrm{~cm}^{-1}$ when the sildenafil was not added in health wine (Figure 5Aa). Although these peaks belonged to sildenafil as well, they might be the Raman characteristic peaks of some kind of traditional Chinese medicines in health wine.

Similar to the SERS spectra of sildenafil in health wine, the SERS peaks at $645,814,1232,1401$, 1530 and $1582 \mathrm{~cm}^{-1}$ increased rapidly when the sildenafil concentration in liquor was increased from 0.1 to $20 \mathrm{mg} / \mathrm{L}$, while those SERS peaks fluctuated greatly in the range of $20-50 \mathrm{mg} / \mathrm{L}$. Moreover, it can be clearly seen that the SERS peak intensities of sildenafil in health wine were generally higher than that in liquor, which indicated that the background difference between health wine and liquor would 
lead to the difference in SERS characteristic peak intensities. In conclusion, 645, 814, 1232, 1401, 1530 and $1582 \mathrm{~cm}^{-1}$ could be qualitatively determined as sildenafil characteristic peaks in health wine and liquor, and a possible reason is shown in Figure 6.

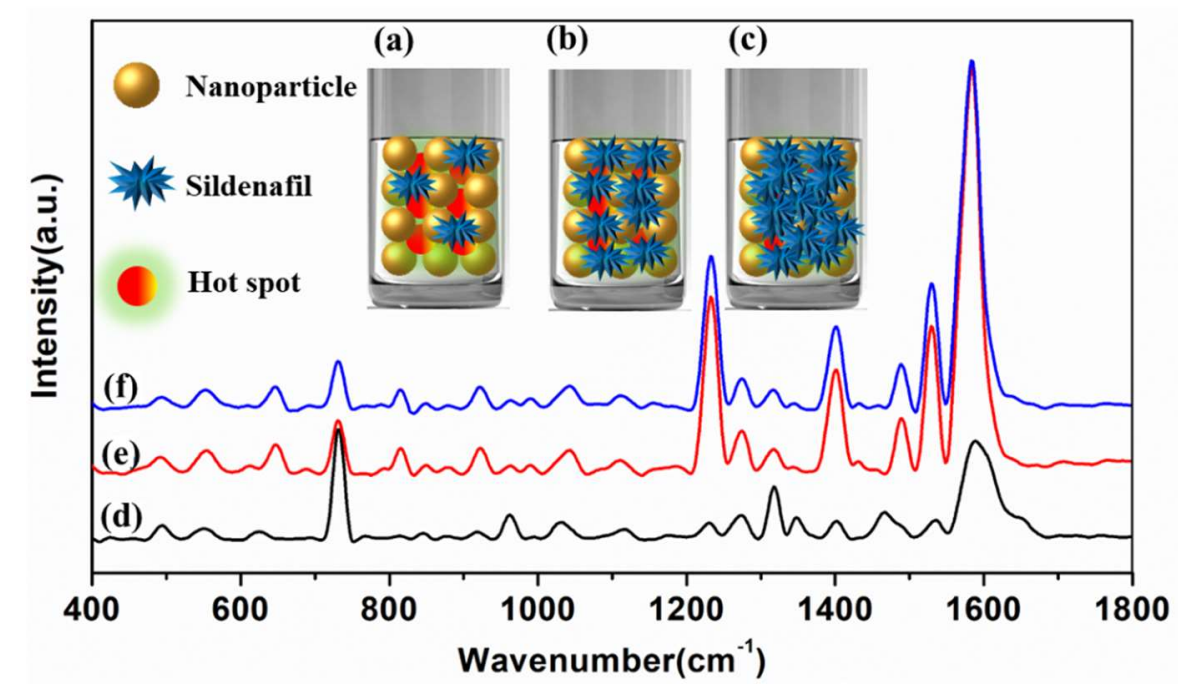

Figure 6. The diagram of the "hot spots" among the sildenafil molecules and nanoparticles. The diagram of the "hot spots" among the nanoparticles with low (a), appropriate (b) and extraordinary high (c) sildenafil concentration. The SERS spectra with low (d), appropriate (e) and extraordinary high (f) sildenafil concentration.

It is well known that the SERS signals can be greatly enhanced by the so-called "hot spots" effect. According to Figure 6, with the constant amount of "hot spots", the "hot spot" effect among the nanoparticles were not completed when the sildenafil concentration was low (Figure 6a). The "hot spot" effect among the nanoparticles gradually increased with the increase of sildenafil concentration, resulting in the rapid enhancement of SERS signals (Figure 6b). When the concentration of sildenafil increased to a certain extent, the "hot spot" effect among the nanoparticle particles tended to be saturated, thus the enhancement effect of the SERS signal was not obvious (Figure 6c).

\subsection{Quantitative Detection of Sildenafil in Health Wine and Liquor}

Moreover, the relationship between Raman peak intensity at 645, 814, 1232, 1401, 1530 and $1582 \mathrm{~cm}^{-1}$ and sildenafil concentration ranging from 0.1 to $50 \mathrm{mg} / \mathrm{L}(0.1,0.2,0.4,0.6,0.8,1,2,4,6,8,10$, $15,20,25,30,35,40,45$ and $50 \mathrm{mg} / \mathrm{L}$ ) in health wine (Figure 7) and liquor (Figure 8) were established. In addition, the linear equations at 645, 814, 1232, 1401, 1530 and $1582 \mathrm{~cm}^{-1}$ are given in Tables 3 and 4 , respectively.

Table 3. The linear equation at $645,814,1232,1401,1530$ and $1582 \mathrm{~cm}^{-1}$ of health wine.

\begin{tabular}{cccccccc}
\hline $\begin{array}{c}\text { Peaks } \\
\left(\mathbf{c m}^{-1}\right)\end{array}$ & Linear Equation & $\begin{array}{c}\text { Range } \\
(\mathbf{m g} / \mathbf{L})\end{array}$ & $\boldsymbol{R}^{\mathbf{2}}$ & $\begin{array}{c}\text { Peaks } \\
\left.\mathbf{( c m}^{-1}\right)\end{array}$ & Linear Equation & $\begin{array}{c}\text { Range } \\
(\mathbf{m g} / \mathbf{L})\end{array}$ & $\boldsymbol{R}^{\mathbf{2}}$ \\
\hline \multirow{3}{*}{645} & $y=27.484 x+52.013$ & $0.1-10$ & 0.9720 & & $y=39.996 x+40.358$ & $0.1-10$ & 0.9650 \\
& $y=76.502 x+24.209$ & $0.1-1$ & 0.9687 & 814 & $y=112.35 x-4.0499$ & $0.1-1$ & 0.9777 \\
& $y=24.832 x+70.683$ & $1-10$ & 0.9816 & & $y=33.846 x+84.522$ & $1-10$ & 0.9819 \\
\hline \multirow{2}{*}{1232} & $y=186.6 x+373.08$ & $0.1-10$ & 0.9101 & & $y=120.74 x+403.59$ & $0.1-10$ & 0.8752 \\
& $y=823.83 x-9.648$ & $0.1-1$ & 0.9803 & 1401 & $y=638.58 x+98.242$ & $0.1-1$ & 0.9722 \\
& $y=140.39 x+702.58$ & $1-10$ & 0.9822 & & $y=86.188 x+649.19$ & $1-10$ & 0.9840 \\
\hline \multirow{2}{*}{1530} & $y=190.96 x+377.12$ & $0.1-10$ & 0.8801 & & $y=520.22 x+1295.2$ & $0.1-10$ & 0.8883 \\
& $y=891.26 x-60.683$ & $0.1-1$ & 0.9891 & 1582 & $y=2587.6 x+68.153$ & $0.1-1$ & 0.9787 \\
& $y=129.74 x+816.6$ & $1-10$ & 0.9701 & & $y=365.32 x+2403.7$ & $1-10$ & 0.9872 \\
\hline
\end{tabular}



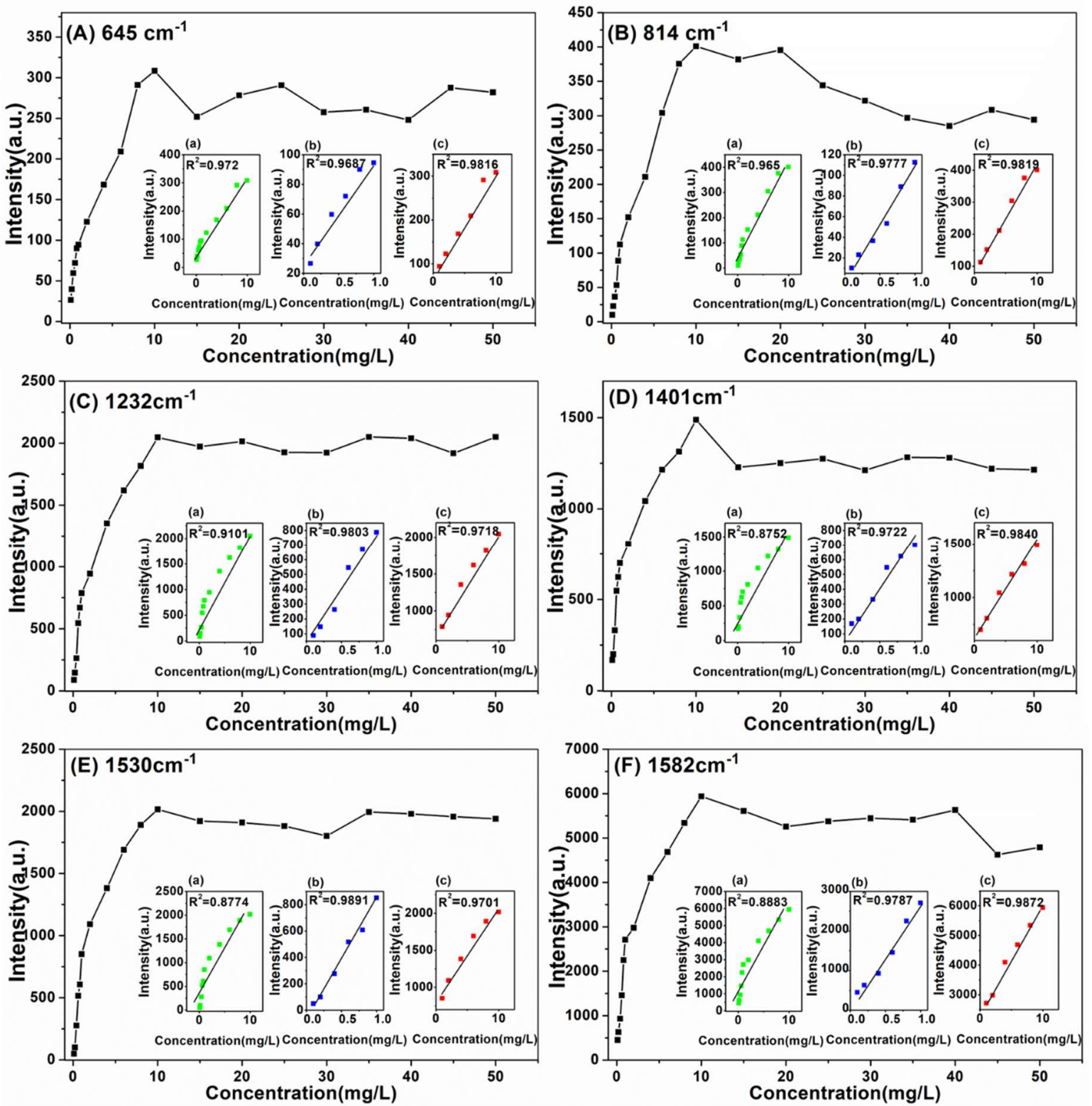

Figure 7. The intensities of SERS peak versus sildenafil concentration in health wine at: $645 \mathrm{~cm}^{-1}$ (A); $814 \mathrm{~cm}^{-1}$ (B); $1232 \mathrm{~cm}^{-1}$ (C); $1401 \mathrm{~cm}^{-1}$ (D); $1530 \mathrm{~cm}^{-1}$ (E); and $1582 \mathrm{~cm}^{-1}$ (F). Inset: The linear calibration plotted in the concentration range: (a) $0.1-10 \mathrm{mg} / \mathrm{L}$; (b) $0.1-1 \mathrm{mg} / \mathrm{L}$; and (c) $1-10 \mathrm{mg} / \mathrm{L}$.

Table 4. The linear equation at $645,814,1232,1401,1530$ and $1582 \mathrm{~cm}^{-1}$ of liquor.

\begin{tabular}{cccccccc}
\hline $\begin{array}{c}\text { Peaks } \\
\left(\mathbf{c m}^{-1}\right)\end{array}$ & Linear Equation & $\begin{array}{c}\text { Range } \\
\mathbf{( m g / L )}\end{array}$ & $\boldsymbol{R}^{\mathbf{2}}$ & $\begin{array}{c}\text { Peaks } \\
\mathbf{( \mathbf { c m } ^ { - 1 } )}\end{array}$ & Linear Equation & $\begin{array}{c}\text { Range } \\
\mathbf{( m g} / \mathbf{L})\end{array}$ & $\boldsymbol{R}^{\mathbf{2}}$ \\
\hline \multirow{3}{*}{645} & $y=29.237 x+6.7438$ & $0.1-20$ & 0.9921 & & $y=17.003 x+18.855$ & $0.1-20$ & 0.9812 \\
& $y=65.767 x+2.1908$ & $0.1-1$ & 0.9944 & 814 & $y=29.237 x+6.749$ & $0.1-1$ & 0.9944 \\
& $y=15.437 x+74.515$ & $1-20$ & 0.9625 & & $y=16.09 x+30.708$ & $1-20$ & 0.9747 \\
\hline \multirow{2}{*}{1232} & $y=106.26 x+251.16$ & $0.1-20$ & 0.9353 & & $y=27.004 x+20.516$ & $0.1-20$ & 0.9944 \\
& $y=342.03 x+10.409$ & $0.1-1$ & 0.9726 & 1401 & $y=43.907 x+9.5066$ & $0.1-1$ & 0.9662 \\
& $y=86.896 x+503.1$ & $1-20$ & 0.9652 & & $y=26.437 x+27.85$ & $1-20$ & 0.9922 \\
\hline \multirow{3}{*}{1530} & $y=96.516 x+593.72$ & $0.1-20$ & 0.8629 & & $y=232.12 x+11.709$ & $0.1-20$ & 0.9896 \\
& $y=824.13 x+93.493$ & $0.1-1$ & 0.9734 & 1582 & $y=112.76 x-11.609$ & $0.1-1$ & 0.9835 \\
& $y=70.364 x+931.57$ & $1-20$ & 0.9816 & & $y=223.49 x+138.28$ & $1-20$ & 0.982 \\
\hline
\end{tabular}



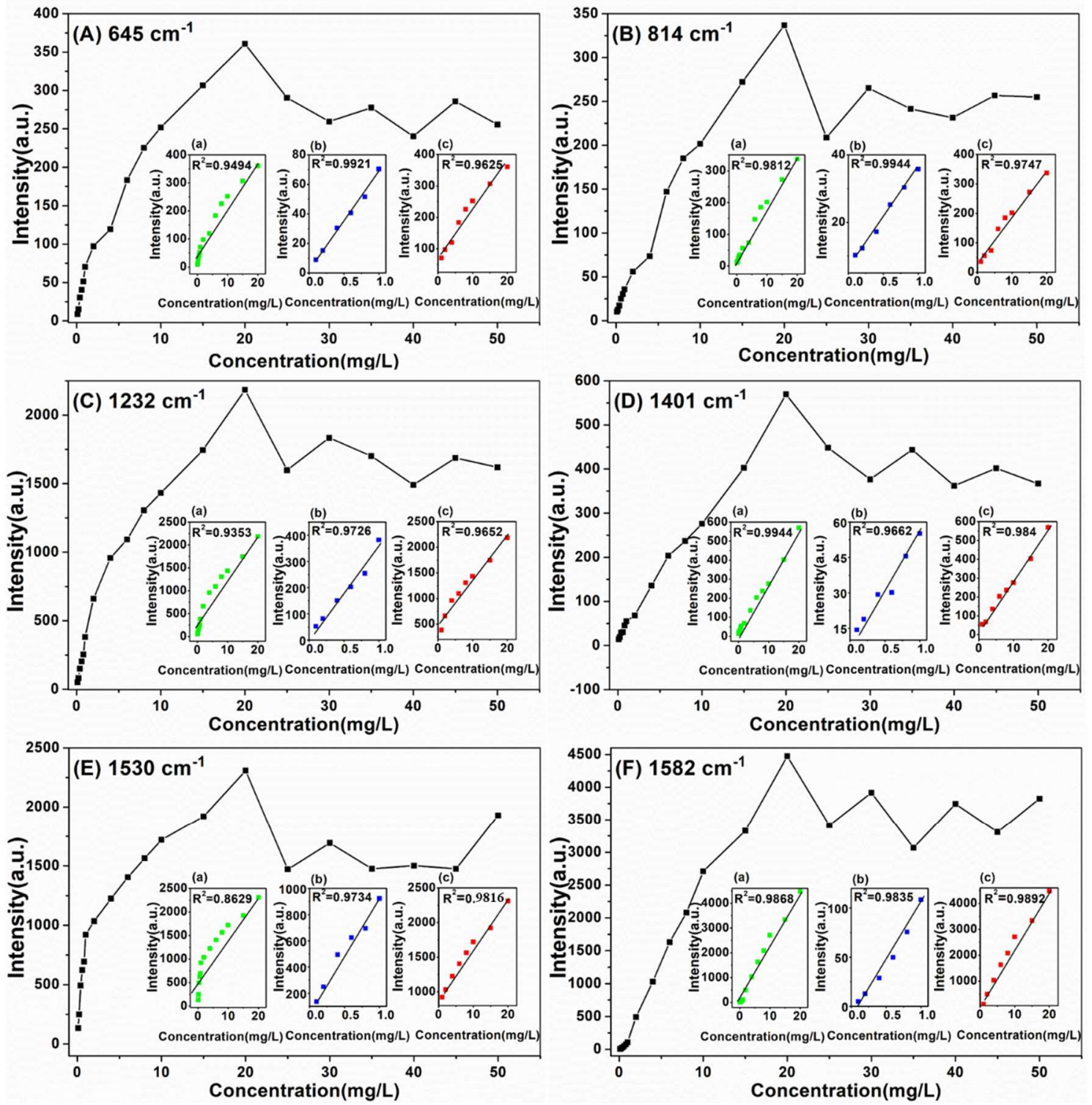

Figure 8. The intensities of SERS peaks versus sildenafil concentration in liquor at: $645 \mathrm{~cm}^{-1}$ (A); 814 $\mathrm{cm}^{-1}$ (B); $1232 \mathrm{~cm}^{-1}$ (C); $1401 \mathrm{~cm}^{-1}$ (D); $1530 \mathrm{~cm}^{-1}$ (E); and $1582 \mathrm{~cm}^{-1}$ (F). Inset: The linear calibration plotted in the concentration range: (a) $0.1-20 \mathrm{mg} / \mathrm{L}$; (b) $0.1-1 \mathrm{mg} / \mathrm{L}$; and (c) $1-20 \mathrm{mg} / \mathrm{L}$.

According to Figure 7 and Table 3, there was a good linear correlation between Raman peak intensity and sildenafil concentration in health wine in each linear regression equation ranging $0.1-1 \mathrm{mg} / \mathrm{L}\left(0.9687<R^{2}<0.9891\right)$ and $1-10 \mathrm{mg} / \mathrm{L}\left(0.9701<R^{2}<0.9840\right)$. Although there was a good linear correlation in the range of $0.1-10 \mathrm{mg} / \mathrm{L}$ at 645 and $814 \mathrm{~cm}^{-1}$, the correlation coefficients were below 0.92 at 1232,1401, 1530 and $1582 \mathrm{~cm}^{-1}$. Therefore, the sildenafil in health wine could be accurately and quantitatively detected by adopting different model in the range of $0.1-10 \mathrm{mg} / \mathrm{L}$.

According to Figure 8 and Table 4, there was a good linear correlation between Raman peak intensity and sildenafil concentration in liquor in each linear regression equation ranging $0.1-1 \mathrm{mg} / \mathrm{L}$ $\left(0.9662<R^{2}<0.9944\right)$ and $1-20 \mathrm{mg} / \mathrm{L}\left(0.9625<R^{2}<0.9922\right)$. Although there was a good linear correlation at 814,1401 and $1582 \mathrm{~cm}^{-1}$, the correlation coefficients were only $0.9494,0.9353$ and 0.8629 at 645,1232 and $1530 \mathrm{~cm}^{-1}$, respectively. Therefore, the sildenafil in liquor could be accurately and quantitatively detected by adopting different models in the range of $0.1-20 \mathrm{mg} / \mathrm{L}$.

From the above analysis, although there were some differences in the detection of sildenafil in health wine and liquor by SERS technique, there was a good linear relationship between the 
intensity and concentration of different Raman characteristic peaks in a certain concentration range, which indicated that it was feasible to use SERS technology for the detection of sildenafil in both health wine and liquor.

\subsection{Model Accuracy Verification}

To verify the accuracy of this detection method of sildenafil, first different concentrations of sildenafil in health wine $(0.5,5 \mathrm{mg} / \mathrm{L})$ and liquor $(0.5,5$ and $13 \mathrm{mg} / \mathrm{L})$ were prepared; each concentration contained nine samples. Second, all samples were detected by SERS based on OTR 202 colloids. Third, the linear regression equations at $645,814,1232,1401,1530$ and $1582 \mathrm{~cm}^{-1}$ were used to predict the sildenafil concentration in health wine and liquor. Tables 5 and 6 present the precision and accuracy for the determination of sildenafil in health wine and liquor, respectively.

Table 5. The precision and accuracy for the determination of sildenafil in health wine.

\begin{tabular}{|c|c|c|c|c|c|c|c|}
\hline \multirow{2}{*}{\multicolumn{2}{|c|}{$\begin{array}{c}\text { Sildenafil Peaks in Health } \\
\text { Wine }\left(\mathrm{cm}^{-1}\right)\end{array}$}} & \multicolumn{6}{|c|}{ Predicted $(\mathrm{mg} / \mathrm{L})$ Mean $+{ }^{a}$ SD } \\
\hline & & \multirow{2}{*}{$\frac{645}{0.472 \pm 0.026}$} & \multirow{2}{*}{$\frac{\mathbf{8 1 4}}{0.522 \pm 0.021}$} & \multirow{2}{*}{$\frac{1232}{0.467 \pm 0.031}$} & \multirow{2}{*}{$\frac{1401}{0.470 \pm 0.024}$} & \multirow{2}{*}{$\frac{1530}{0.480 \pm 0.013}$} & \multirow{2}{*}{$\frac{1582}{0.444 \pm 0.029}$} \\
\hline Added (mg/L) & 0.5 & & & & & & \\
\hline a RSD & & 5.51 & 3.92 & 6.78 & 5.14 & 2.89 & 6.66 \\
\hline Recover & & 94.41 & 104.42 & 93.5 & 94.08 & 96.11 & 88.92 \\
\hline Added (mg/L) & 5 & $4.89 \pm 0.51$ & $4.97 \pm 0.37$ & $4.93 \pm 0.22$ & $4.84 \pm 0.22$ & $5.02 \pm 0.13$ & $4.88 \pm 0.42$ \\
\hline a RSD & & 5.11 & 7.65 & 4.51 & 4.62 & 2.53 & 4.21 \\
\hline Recover & & 97.87 & 99.38 & 98.60 & 96.89 & 100.43 & 97.62 \\
\hline
\end{tabular}

${ }^{\text {a }} \mathrm{SD}$ (standard deviation); RSD (relative standard deviation).

Table 6. The precision and accuracy for the determination of sildenafil in liquor.

\begin{tabular}{|c|c|c|c|c|c|c|c|}
\hline \multirow{2}{*}{\multicolumn{2}{|c|}{$\begin{array}{l}\text { Sildenafil Peaks in Health } \\
\text { Liquor }\left(\mathrm{cm}^{-1}\right)\end{array}$}} & \multicolumn{6}{|c|}{ Predicted $(m g / L)$ Mean + SD } \\
\hline & & \multirow{2}{*}{$\frac{\mathbf{6 4 5}}{0.483 \pm 0.039}$} & \multirow{2}{*}{$\frac{814}{0.522 \pm 0.036}$} & \multirow{2}{*}{$\begin{array}{c}1232 \\
0.498 \pm 0.022\end{array}$} & \multirow{2}{*}{$\frac{1401}{0.512 \pm 0.043}$} & \multirow{2}{*}{$\begin{array}{c}1530 \\
0.534 \pm 0.026\end{array}$} & \multirow{2}{*}{$\frac{1584}{0.464 \pm 0.025}$} \\
\hline Added $(\mathrm{mg} / \mathrm{L})$ & 0.5 & & & & & & \\
\hline & & 8.07 & 6.98 & 4.59 & 8.35 & 4.95 & 5.44 \\
\hline \multicolumn{2}{|c|}{ Recovery (\%) } & 96.61 & 104.45 & 99.78 & 102.32 & 106.78 & 92.77 \\
\hline Added $(\mathrm{mg} / \mathrm{L})$ & 5 & $4.71 \pm 0.32$ & $4.77 \pm 0.28$ & $4.93 \pm 0.23$ & $4.50 \pm 0.34$ & $5.14 \pm 0.34$ & $4.89 \pm 0.43$ \\
\hline \multicolumn{2}{|c|}{ a $\operatorname{RSD}(\%)$} & 6.67 & 5.90 & 4.88 & 7.62 & 6.70 & 8.70 \\
\hline \multicolumn{2}{|c|}{ Recovery (\%) } & 94.31 & 95.44 & 98.60 & 90.09 & 102.80 & 97.86 \\
\hline Added $(\mathrm{mg} / \mathrm{L})$ & 13 & $12.78 \pm 0.85$ & $12.08 \pm 0.89$ & $13.24 \pm 0.63$ & $12.33 \pm 0.90$ & $12.70 \pm 0.97$ & $12.69 \pm 0.98$ \\
\hline \multicolumn{2}{|c|}{ a $\operatorname{RSD}(\%)$} & 6.72 & 7.38 & 4.66 & 7.61 & 7.62 & 7.68 \\
\hline \multicolumn{2}{|c|}{ Recovery (\%) } & 98.36 & 92.99 & 101.84 & 94.90 & 97.73 & 97.64 \\
\hline
\end{tabular}

a SD (standard deviation); RSD (relative standard deviation).

According to Table 5, the sildenafil concentration in health wine could be well predicted using the linear regression equations at $645,814,1232,1401,1530$ and $1582 \mathrm{~cm}^{-1}$. The relative standard deviation (RSD) was less than $6.78 \%$ and $7.65 \%$ for two added concentrations, respectively. The recoveries were in the ranges of $88.92-104.42 \%$ and $97.62-100.43 \%$, respectively. Moreover, the linear regression equations at $1530 \mathrm{~cm}^{-1}$ had the best precision and accuracy for $0.5 \mathrm{mg} / \mathrm{L}$ (predicted + SD: $0.480 \pm 0.013$; RSD: 2.89; Recovery: 96.11), $5 \mathrm{mg} / \mathrm{L}$ (predicted + SD: $5.02 \pm 0.13$; RSD: 2.53; Recovery: 100.43) and $13 \mathrm{mg} / \mathrm{L}$.

According to Table 6, the sildenafil concentration in liquor could also be well predicted using the linear regression equations at $645,814,1232,1401,1530$ and $1582 \mathrm{~cm}^{-1}$. The RSD were less than $8.07 \%, 8.70 \%$ and $7.68 \%$, respectively, at the three added concentrations. The recoveries were in the ranges of $92.77-104.45 \%, 90.09-102.80 \%$ and $92.99-101.84 \%$, respectively. Moreover, the linear regression equations at $1232 \mathrm{~cm}^{-1}$ had the best precision and accuracy for $0.5 \mathrm{mg} / \mathrm{L}$ (predicted + SD: $0.498 \pm$ 0.022; RSD: 4.59; Recovery: 99.78), $5 \mathrm{mg} / \mathrm{L}$ (predicted + SD: $4.93 \pm 0.23$; RSD: 4.88; Recovery: 98.60) and $13 \mathrm{mg} / \mathrm{L}$ (predicted + SD: $13.24 \pm 0.63$; RSD: 4.66; Recovery: 101.84). From the results above, we conclude that the application of our method for sildenafil detection has excellent practical value. 


\section{Materials and Methods}

\subsection{Chemicals}

The reagents used in this experiment included sildenafil (99.8\% purity, Sigma-Aldrich, Beijing, China), methanol (chromatographically pure, Amethyst Chemicals, Beijing, China), R6G (96.01\% purity, Sigma-Aldrich, Beijing, China), health wine (Jinpai Co., Ltd., DaYe, China) and liquor (Beijing Red Star Co., Ltd. Beijing, China). In addition, the OTR 202 colloids produced by Opto Trace Technologies, Inc. (Suzhou, China) were used as SERS substrate in this study.

\subsection{Instruments}

The experimental instruments included: (1) RmTracer-200-HS portable Raman spectrometer combined with a $785 \mathrm{~nm}$ excitation wavelength diode-stabilized stimulator (Opto Trace Technologies, Inc., Mountain View, CA, USA); (2) FEI Tecnai G2 F20 S-TWIN transmission electron microscope (FEI Company, Hillsboro, OR, USA); and (3) Vortex-Genie 2/2T vortex mixer (Shanghai Ling early Environmental Protection Instrument Co., Ltd, Shanghai, China).

\subsection{Sample Preparation}

The sample preparation process was as follows. First, the standard sildenafil was diluted to $1000 \mathrm{mg} / \mathrm{L}$ with methanol. Second, the standard solution of $1000 \mathrm{mg} / \mathrm{L}$ was diluted to 0-50 mg/L with health wine and liquor, respectively. For each concentration the sample was prepared in triplicate.

\subsection{SERS Measurement}

Before Raman spectra acquisition, the instrument was calibrated using a $785 \mathrm{~nm}$ excitation wavelength. The parameters were set as follows: a power of $200 \mathrm{mw}$, a scanning range of $200-3300 \mathrm{~cm}^{-1}$, an optical resolution of $2 \mathrm{~cm}^{-1}$, an integration time of $10 \mathrm{~s}$ and an average spectral value of 3 times. When collecting the SERS of samples, $500 \mu \mathrm{L}$ OTR 202 colloids and $100 \mu \mathrm{L}$ test solution were added in turn into a $2 \mathrm{~mL}$ quartz bottle, and then it was placed at a liquid sample pool.

\section{Conclusions}

In this paper, we report a rapid and quantitative determination method of sildenafil in health wine and liquor based on SERS with OTR 202 colloids. We found that the Raman EF of OTR 202 colloids could reach $1.84 \times 10^{7}$ and the proposed method showed good performance for sildenafil in health wine and liquor detection and the LODs were found to be as low as $0.1 \mathrm{mg} / \mathrm{L}$; both were far lower than $1 \%$. Therefore, the presented method can be successfully applied for the quantification of natural healthcare products. Moreover, there was a good linear correlation between Raman peak intensity and sildenafil concentration in both health wine $\left(R^{2}=0.9891\right)$ and liquor $\left(R^{2}=0.9944\right)$ at certain concentration ranges. It was indicated that the application of SERS technique for the rapid detection of sildenafil was feasible and reliable. Overall, the SERS method with OTR 202 colloids enhancement developed through this study provides a novel, rapid and accurate approach to quantitatively determine sildenafil in health wine and liquor, which could meet the requirements of sildenafil determination in other alcoholic drinks.

Author Contributions: S.X. and Y.H. conceived the idea and associated data. S.X. carried out the experimental work and drafted the manuscript. Y.H. co-wrote the paper with S.X. All authors contributed to reviewing and improving the manuscript.

Funding: Funding was provided by major science and technology projects in Zhejiang (2015C02007) and National Key R\&D program of China (2018YFD0101002).

Conflicts of Interest: The authors declare no conflict of interest. 


\section{References}

1. Singh, S.; Prasad, B.; Savaliya, A.A.; Shah, R.P.; Gohil, V.M.; Kaur, A. Strategies for characterizing sildenafil, vardenafil, tadalafil and their analogues in herbal dietary supplements, and detecting counterfeit products containing these drugs. TrAC Trends Anal. Chem. 2009, 28, 13-28. [CrossRef]

2. Che, N.M.; Nor, N.M.; Lajis, R.; Harn, G.L. Identification of sildenafil, tadalafil and vardenafil by gas chromatography-mass spectrometry on short capillary column. J. Chromatogr. A 2009, 1216, 8426-8430.

3. Huang, C.A.; Yeh, K.-Y.; Cheng, Y.-Y.; Dubey, K.N.; Chiu, W.A.; Tsai, T.-H. Investigation of Interactive Activity of Electro-Acupuncture on Pharmacokinetics of Sildenafil and Their Synergistic Effect on Penile Blood Flow in Rats. Int. J. Mol. Sci. 2018, 19, 2153. [CrossRef] [PubMed]

4. Song, Y.; Wang, Y.Y.; Zhang, Y.; Wang, S. Development of enzyme-linked immunosorbent assay for rapid determination of sildenafil in adulterated functional foods. Food Agric. Immunol. 2012, 23, 338-351. [CrossRef]

5. Damiano, F.; Silva, C.; Gregori, A.; Vacondio, F.; Mor, M.; Menozzi, M.; Giorgio, D.D. Analysis of illicit dietary supplements sold in the Italian market: identification of a sildenafil thioderivative as adulterant using UPLC-TOF/MS and GC/MS. Sci. Justice 2014, 54, 228-237. [CrossRef] [PubMed]

6. Vaysse, J.; Gilard, V.; Balayssac, S.; Zedde, C.; Martino, R.; Malet-Martino, M. Identification of a novel sildenafil analogue in an adulterated herbal supplement. J. Pharm. Biomed. Anal. 2012, 59, 58-66. [CrossRef]

7. Huang, Y.C.; Lee, H.C.; Lin, Y.L.; Lin, Y.T.; Tsai, C.F.; Cheng, H.F. Identification of a new sildenafil analogue adulterant, desethylcarbodenafil, in an herbal supplement. Food Addit. Contam. Part A Chem. Anal. Control Expo. Risk Assess. 2016, 33, 1637-1642. [CrossRef]

8. Ying, Z.; Zhiqiang, H.; Li, D.; Hongfei, Y.; Meiling, W.; Shaohua, Z. Simultaneous determination of yohimbine, sildenafil, vardenafil and tadalafil in dietary supplements using high-performance liquid chromatography-tandem mass spectrometry. J. Sep. Sci. 2015, 33, 2109-2114.

9. Challa, B.R.; Awen, B.Z.; Chandu, B.R.; Khagga, M.; Bannoth, C.K.; Kanala, K.; Shaik, R.P.; Peraman, R.; Gogineni, R. Sildenafil and N-desmethyl sildenafil quantification in human plasma by HPLC coupled with ESI-MS/MS detection: Application to bioequivalence study. Anal. Methods 2010, 2, 1043-1050. [CrossRef]

10. Al-Hroub, H.; Alkhawaja, B.; Alkhawaja, E.; Arafat, T. Sensitive and rapid HPLC-UV method with back-extraction step for the determination of sildenafil in human plasma. J. Chromatogr. B Anal. Technol. Biomed. Life Sci. 2016, 1009-1010, 1-6. [CrossRef]

11. Altıkka, G.; Atkosar, Z.; Sener, E.; Tunçel, M. FIA of sildenafil citrate using UV-detection. J. Pharm. Biomed. Anal. 2001, 25, 339-342. [CrossRef]

12. Sabina, S.R.; Luca, A.; Xavier, D.L.T.; Francesco, B. A gas chromatography/mass spectrometry method for the determination of sildenafil, vardenafil and tadalafil and their metabolites in human urine. Rapid Commun. Mass Spectrom. 2010, 24, 1697-1706.

13. Jeong, Y.D.; Suh, S.I.; Jin, Y.K.; In, M.K.; Paeng, K.J. Simultaneous Determination of Sildenafil, Tadalafil, and Vardenafil in Pharmaceutical Preparations by High-Temperature Gas Chromatography/Mass Spectrometry. Chromatographia 2016, 79, 1671-1678. [CrossRef]

14. Reddy, T.S.; Reddy, A.S.; Devi, P.S. Quantitative determination of sildenafil citrate in herbal medicinal formulations by high-performance thin-layer chromatography. Jpc-J. Planar Chromatogr. -Mod. Tlc 2006, 19, 427-431. [CrossRef]

15. Liu, Y.R.; Hai-Sheng, G.E.; Zhao, K.H.; Ling, Y.U.; Zhang, C. Determination of sildenafil citrate added in traditional Chinese medicines and health care products by thin layer chromatographic surface-enhanced Raman spectroscopic method. Chin. J. Pharm. Anal. 2014, 34, 1241-1246.

16. Said, M.M.; Gibbons, S.; Moffat, A.C.; Zloh, M. Rapid detection of sildenafil analogue in Eurycoma longifolia products using a new two-tier procedure of the near infrared (NIR) spectra database. Food Chem. 2014, 158, 296-301. [CrossRef]

17. Vredenbregt, M.J.; Blok-Tip, L.; Hoogerbrugge, R.; Barends, D.M.; Kaste, D.D. Screening suspected counterfeit Viagra ${ }^{\circledR}$; and imitations of Viagra ${ }^{\circledR}$; with near-infrared spectroscopy. J. Pharm. Biomed. Anal. 2006, 40, 840-849. [CrossRef]

18. Ramirez-Mendiola, B.; Flores-Perez, C.; Garcia-Alvarez, R.; Juarez-Olguin, H.; Flores-Perez, J.; Chavez Pacheco, J.L. A reliable method to quantify sildenafil and its metabolite $N$-demethylsildenafil by HPLC in plasma of children. Drug Res. 2013, 63, 473-476. [CrossRef] 
19. Orsi, D.D.; Pellegrini, M.; Marchei, E.; Nebuloni, P.; Gallinella, B.; Scaravelli, G.; Martufi, A.; Gagliardi, L.; Pichini, S. High performance liquid chromatography-diode array and electrospray-mass spectrometry analysis of vardenafil, sildenafil, tadalafil, testosterone and local anesthetics in cosmetic creams sold on the Internet web sites. J. Pharm. Biomed. Anal. 2009, 50, 362-369. [CrossRef]

20. Chee-Leong, K.; Xiaowei, G.; Min-Yong, L. Application of Orbitrap-mass spectrometry to differentiate isomeric sildenafil- and thiosildenafil-like analogues used for the adulteration of dietary supplements. Food Addit. Contam. Part A Chem. Anal. Control Expo. Risk Assess. 2015, 32, 1737-1748.

21. Liew, K.B.; Loh, G.O.; Tan, Y.T.; Peh, K.K. Simultaneous quantification of sildenafil and N-desmethyl sildenafil in human plasma by UFLC coupled with ESI-MS/MS and pharmacokinetic and bioequivalence studies in Malay population. Biomed. Chromatogr. 2015, 29, 953-960. [CrossRef] [PubMed]

22. Yaroshenko, D.V.; Grigoriev, A.V.; Sidorova, A.A.; Kartsova, L.A. Chromatographic determination of sildenafil in blood plasma using spectrophotometric and mass-spectrometric detection. J. Anal. Chem. 2013, 68, 801-808. [CrossRef]

23. Huiyuan, G.; Zhiyun, Z.; Baoshan, X.; Arnab, M.; Craig, M.; White, J.C.; Lili, H. Analysis of Silver Nanoparticles in Antimicrobial Products Using Surface-Enhanced Raman Spectroscopy (SERS). Environ. Sci. Technol. 2015, 49, 4317-4324.

24. He, Y.; Xiao, S.; Dong, T.; Nie, P. Gold Nanoparticles for Qualitative Detection of Deltamethrin and Carbofuran Residues in Soil by Surface Enhanced Raman Scattering (SERS). Int. J. Mol. Sci. 2019, 20, 1731. [CrossRef] [PubMed]

25. Meng, L.; Gu, H.; Yuan, X.; Gao, J.; Cai, T. Investigation of 3D silvernanodendrite@glass as surface-enhanced Raman scattering substrate for the detection of Sildenafil and GSH. J. Mol. Struct. 2012, 1029, 75-80.

26. Mao, D.Z.; Weng, X.X.; Yang, Y.J. Rapid screening of sildenafil and tadalafil adulterated in healthcare products by Micro-Raman spectroscopy. J. Raman Spectrosc. 2012, 43, 1985-1990. [CrossRef]

27. Hang, Z.; Hasi, W.; Lin, B.; Han, S.; Sha, X.; Jia, S.; Lou, X.; Lin, D.; Lv, Z. Rapid Detection of Sildenafil Drugs in Liquid Nutraceuticals Based on Surface-Enhanced Raman Spectroscopy Technology. Chin. J. Chem. 2017, 35, 1522-1528.

28. Zhang, Y.; Huang, X.; Liu, W.; Cheng, Z.; Chen, C.; Yin, L. Analysis of Drugs Illegally Added into Chinese Traditional Patent Medicine Using Surface-enhanced Raman Scattering. Anal. Sci. 2013, 29, 985-990. [CrossRef]

29. Wu, J.; Zhang, L.; Bu, X.; Li, P.; Zhao, B.; Tian, Y. Determination of the illegal adulteration of natural healthcare products with chemical drugs using surface-enhanced Raman scattering. Analyst 2018, 143, 5202-5209. [CrossRef]

30. Lei, L.; Fangfang, Q.; Pengcheng, N.; Hui, Z.; Bingquan, C.; Yong, H. Rapid and Quantitative Determination of Sildenafil in Cocktail Based on Surface Enhanced Raman Spectroscopy. Molecules 2019, 24, 1790.

31. Qin, X.; Guo, X.; Li, X.; Ye, Y.; Wu, Y.; Ying, W.; Yang, H. Template-Free Synthesis of SERS-Active Gold Nanopopcorn for Rapid Detection of Chlorpyrifos Residues. Sens. Actuators B Chem. 2017, 241, 1008-1013.

32. Dong, T.; Lin, L.; He, Y.; Nie, P.; Qu, F.; Xiao, S. Density Functional Theory Analysis of Deltamethrin and Its Determination in Strawberry by Surface Enhanced Raman Spectroscopy. Molecules 2018, 23, 1458. [CrossRef] [PubMed]

33. Lin, L.; Dong, T.; Nie, P.; Qu, F.; He, Y.; Chu, B.; Xiao, S. Rapid Determination of Thiabendazole Pesticides in Rape by Surface Enhanced Raman Spectroscopy. Sensors 2018, 18, 1082. [CrossRef] [PubMed]

34. Luo, H.; Huang, Y.; Lai, K.; Rasco, B.A.; Fan, Y. Surface-enhanced Raman spectroscopy coupled with gold nanoparticles for rapid detection of phosmet and thiabendazole residues in apples. Food Control 2016, 68, 229-235. [CrossRef]

35. Xiaoyu, G.; Yichen, F.; Shuyue, F.; Hui, W.; Tianxi, Y.; Ying, W.; Haifeng, Y. Improving SERS activity of inositol hexaphosphate capped silver nanoparticles: Fe3+ as a switcher. Inorg. Chem. 2014, 53, 7227-7232.

36. Zhu, W.L.; Tan, X.J.; Puah, C.M.; Gu, J.D.; Jiang, H.L.; Chen, K.X.; Felder, C.E.; Silman, I.; Sussman, J.L. How Does Ammonium Interact with Aromatic Groups? A Density Functional Theory (DFT/B3LYP) Investigation. J. Phys. Chem. A 2000, 104, 9573-9580. [CrossRef]

(C) 2019 by the authors. Licensee MDPI, Basel, Switzerland. This article is an open access article distributed under the terms and conditions of the Creative Commons Attribution (CC BY) license (http://creativecommons.org/licenses/by/4.0/). 